elSSN : 2654-4687 ; pISSN : 2654-3894

https://doi.org/10.17509/jithor.v3i2.25157

jithor@upi.edu

http://ejournal.upi.edu/index.php/Jithor

Volume 3, No. 2, October 2020

\title{
TOURIST EXPERIENCE DARI SMART TOURISM DESTINATION, STUDI KASUS DI KOTA BANDUNG, JAWA BARAT, INDONESIA
}

\author{
Linda Puspita Sari ${ }^{(1)^{*}}$, Any Noor ${ }^{(2)}$, Acep Unang Rahayu ${ }^{(3)}$ \\ (1) Program Studi Manajemen Perjalanan, Sekolah Tinggi Pariwisata Bandung \\ (2) Politeknik Negeri Bandung \\ (3) Sekolah Tinggi Pariwisata Bandung \\ lindapuspita1990@gmail.com, anynoor@polban.ac.id, acp@stpbandung.ac.id
}

Submitted: 2 June 2020 Revised: 1 August 2020

Accepted: 3 August 2020

\begin{abstract}
ABSTRAK
Tujuan penelitian ini adalah untuk memahami smart tourism destination dalam mempengaruhi tourist experience di Kota Bandung. Metode kuantitatif dilakukan pada penelitian ini. Data dikumpulkan dengan cara penyebaran kuesioner kepada para wisatawan yang datang ke Kota Bandung menggunakan smartphone juga melakukan wawancara dengan Dinas Kebudayaan dan Pariwisata (Disbudpar) Kota Bandung untuk menambah data mengenai penelitian ini. Analisis data metode linear berganda dilakukan dengan menggunakan SPSS berdasarkan data dengan skala ordinal dan analisis deskriptif. Hasil penelitian ini menunjukkan bahwa smart tourism destination berpengaruh pada tourist experience di Bandung. Penelitian ini diharapkan dapat menjadi acuan pengembangan konsep "smart tourism destination" yang dapat meningkatkan tourist experience di Kota Bandung.
\end{abstract}

Kata Kunci: Bandung, Smart Tourism Destination, Tourist Experience

\section{TOURIST EXPERIENCE FROM SMART TOURISM DESTINATION, A CASE STUDY IN BANDUNG CITY, WEST JAVA, INDONESIA}

\section{ABSTRACT}

The aim of this study is to know the influence of smart tourism destination $(X)$ on the tourist experience $(Y)$ in Bandung city. The research method is quantitative. The data collection is carried out by distributing the questionnaires to the tourists who visit Bandung using the smartphone and also held the interview with Dinas Kebudayaan dan Pariwisata (Disbudpar) of Bandung City to add the data for this research. Multiple linear methods with SPSS used to analyze the data as well as ordinal scale and descriptive analysis. The results showed that smart tourism destination is influencing tourist experience in Bandung. The result hopefully could be the reference on the development of the concept "smart tourism destination" that can improve tourist experience in Bandung.

Keywords: Bandung, Smart Tourism Destination, Tourist Experience

\section{PENDAHULUAN}

Smart city adalah istilah baru yang berkembang untuk menggambarkan suatu kota yang memanfaatkan perkembangan teknologi dalam berbagai aktivitas sosial, ekonomi, dan lingkungan hidup. Teknologi 
yang mendasari perkembangan smart city diantaranya komunikasi dan jaringan internet (seperti $W i-F i$, evolusi $3 \mathrm{G}$ ke $4 \mathrm{G}$, jaringan 5G), IoT (Internet of Things), cloud, open data, big data, data analytics, dan citizen engagement (aplikasi smartphone dan web, crowdsourcing) (Lea, 2017). Banyak insfrastruktur serta sarana dan prasarana pariwisata dikembangkan berdasarkan konsep Smart Tourism Destination. Aplikasi dalam Smart Tourism Destination yang sudah banyak digunakan diantaranya VR (Virtual Reality), AR (Augmented Reality) untuk meningkatkan lingkungan pengalaman digital pada suatu tempat wisata, vehicle tracking, dan sistem monitor untuk mendapatkan informasi real-time. Aplikasi digunakan untuk meningkatkan efisiensi energi pada "green hotels" dalam mengurangi konsumsi tenaga listrik dan meminimlakan polusi. Aplikasi lainnya digunakan untuk mendukung ketersediaan paket wisata, alih bahasa, pemanduan untuk wisatawan, akses informasi mengenai atraksi wisata terdekat melalui perangkat seluler (Buhalis \& Amaranggana, 2014).

Bandung adalah ibu kota dan kota terbesar di provinsi Jawa Barat yang menerapkan konsep smart city dengan jaringan koneksi yang terintegrasi dalam berbagai bidang. Di era digital, beragam teknologi diaplikasikan untuk memaksimalkan potensi destinasi wisata menuju smart tourism destination. Dukungan teknologi yang terintegerasi berfungsi untuk memaksimalkan potensi dan bisnis pariwisata.

Dinas Budaya dan Pariwisata (Disbudpar) Kota Bandung memberikan dukungan kemudahan infrastuktur dalam menciptakan smart tourism destination melalui kolaborasi dengan beragam layanan secara online, seperti transportasi online (Grab) dan layanan kamar online (RedDoorz) yang bertujuan untuk menghubungkan sektor pariwisata dengan konsumen (wisatabdg.com, 2018). Beragam layanan akses disediakan Kota Bandung untuk memudahkan konsumen mendapatkan layanan secara online, seperti penyediaan free Wi-fi sebanyak 10.000 akses (Kamil, 2014) dan penerapan $Q R$ Codes untuk 650 sepeda Obike yang ditempatkan di beberapa hotel di Kota Bandung (Mauludy, 2017).

Tingginya keiinginan Kota Bandung dalam memberikan layanan elektronik bagi kemudahan wisatawan untuk mendapatkan informasi wisata secara online telah meningkatkan kesiapan Kota Bandung sebagai smart tourism destination, yang seluruh kesiapannya diarahkan secara digital. Tentunya, hal ini sejalan dengan karakteristik wisatawan yang tinggi dengan kemampuan menggunakan telepon pintar untuk mengakses beragam layanan wisata secara online.

Jumlah wisatawan yang datang ke Kota Bandung sejak tahun 2014 sampai tahun 2017 berfluktuasi antara 4,8 juta sampai 6 juta wisatawan, dapat dilihat berdasarkan pada tabel 1 berikut:

Tabel 1. Kunjungan Wisatawan di Kota
\begin{tabular}{ll} 
Bandung \\
\cline { 2 - 2 } Tahun & Jumlah \\
\hline $\mathbf{2 0 1 4}$ & 5.807 .564 \\
\hline $\mathbf{2 0 1 5}$ & 6.061 .094 \\
\hline $\mathbf{2 0 1 6}$ & 5.000 .625 \\
\hline $\mathbf{2 0 1 7}$ & 4.801 .108 \\
\hline
\end{tabular}

Sumber: Badan Pusat Statistik, 2018

Jika dirata-ratakan, terdapat sekitar 5,3 juta wisatawan setiap tahun. Karakteristik wisatawan yang datang ke Kota Bandung dipengaruhi oleh beragam informasi yang didapat secara online. Hasil studi yang dilakukan oleh Noor, dkk (2019) mengenai perilaku wisatawan menggunakan sosial media di Indonesia, menjelaskan bahwa 92\% wisatawan mencari informasi secara online mengenai destinasi wisata sebelum berwisata. Lebih jauh, hasil studi yang dilakukan Noor dkk (2019) juga menggarisbawahi bahwa sebelum melakukan perjalanan, wisatawan melakukan pencarian informasi mengenai perjalanan wisata, seperti harga (80\%), akomodasi di destinasi (74\%), makanan di destinasi $(72 \%)$, transportasi ke destinasi (70\%), atraksi wisata $(67 \%)$, transportasi di destinasi (58\%), souvenir di destinasi (54\%), 
budaya dan tradisi $(43 \%)$ serta program promosi wisata di destinasi (38\%). Hal tersebut menjelaskan bahwa wisatawan memiliki karakteristik yang terhubung secara online dengan beragam media elektronik.

Karakteristik wisatawan yang berkunjung ke Kota Bandung tentunya sesuai dengan atribut kota tersebut sebagai smart tourism destination, yaitu sebagai wisatawan yang menggunakan beragam aplikasi online dalam berwisata. Terdapat penelitian terdahulu mengenai smart tourism destinations enhancing tourism experience thorugh personalisation of service (Buhalis \& Amaranggana, 2014) yang menemukan bahwa beragam aspek pelayanan diharapkan oleh wisatawan dengan informasi real time untuk menentukan keputusan berwisata dan mendampingi wisatawan menjelajah suatu destinasi yang meningkatkan pengalaman dari suatu destinasi. Namun demikian, dalam hal ini tidak hanya informasi real time yang digunakan oleh wisatawan, tetapi juga bagaimana pengalaman wisatawan (tourist experience) menggunakan beragam media aplikasi yang telah disediakan Kota Bandung sebagai smart tourism destination menjadi landasan studi ini. Dengan demikian, tujuan dalam studi ini adalah memahami bagaimana smart tourism destination mempengaruhi tourist experience di Kota Bandung.

\section{TINJAUAN PUSTAKA}

\section{Smart Tourism Destination}

Tidak ada satu definisi standar mengenai STD (Del Chiappa \& Baggio, 2015), tetapi Spanish Innovation Fostering Institution SEGITTUR bersama agensi standardisasi negara-negara AENOR mendefinisikan STD sebagai sebuah area wisatawan yang inovatif, dapat diakses oleh semua orang melalui pembangunan infrastruktur teknologi yang menjamin perkembangan berkelanjutan dari suatu destinasi, memfasilitasi interaksi wisatawan yang terintegerasi dengan sekitar, serta memperkaya kualitas pengalaman wisatawan di destinasi dan masyarakat sekitar (de Ávila, Lancis et.al, 2015).
Konsep STD banyak menarik perhatian untuk diteliti dan banyak dipertimbangkan sebagai evolusi masa kini yang berhubungan dengan konsep 'destinasi' (Jovicic, 2017). Teori perkembangan STD masih terbatas, terutama jika dihubungkan dengan destinasi, hal ini masih dianggap sebagai sesuatu yang kompleks dan berubah-ubah, serta dikembangan secara bertahap (Pearce, 2014). Teknologi STD mengembangkan unsur baru, seperti Internet of Thing (IoT) (Koo et al, 2016), teknologi menjadi ruang untuk keterhubungan antar stakeholder (Gretzel et al, 2015).

Kota Bandung dalam perkembangannya sebagai STD sudah memulai pembangunan infrastruktur melalui penyediaan layanan berbasis digital untuk beragam fasilitas pariwisata. Sejauh ini, penerapan STD yang baik di Kota Bandung didukung oleh beberapa pelaku utama di bidang pariwisata. Sesuai dengan beragam studi yang berkembang mengenai STD, Kota Bandung menerapkan suatu konsep teknologi terbaru yang mengintegerasikan tujuan wisata untuk meningkatkan pengalaman berwisata (tourist experience) melalui kecanggihan dan kemudahan teknologi.

\section{Dimensi Smart Tourism Destination}

Dimensi STD yang dihasilkan dari penelitian terdahulu masih sangat terbatas, karena studi mengenai ini masih belum banyak dilakukan. Untuk mencapai dimensi STD perlu dicari mekanisme yang dapat mengarahkan inovasi di destinasi wisata yang telah dikembangkan menggunakan Teknologi Informasi dan Komunikasi yang dapat meningkatkan aksesibilitas dan keberlanjutan. Menurut De Ávila, Lancis et.al (2015) ada empat pondasi untuk dimensi STD, diantaranya adalah teknologi (21 th century tourist information, free wi-fi, mobile apps, $Q R$ Codes, online maps), inovasi (promosi wisata online, komunikasi dengan aplikasi online, pengembangan produk wisata), aksesibilitas (kemudahan transportasi wisata, akses layanan informasi wisata) dan sustainability (peningkatan perdagangan/perkebunan, kerajinan tangan, 
pemeliharaan warisan budaya). Keempat dimensi STD ini sesuai dengan kondisi Kota Bandung, sehingga keempat dimensi tersebut tepat menjadi variabel utama dalam penelitian ini. Kota Bandung adalah salah satu kota yang telah menerapkan smart city dengan konsep yang menitikberatkan pada penggunaan teknologi dan inovasi suatu kota. Kota Bandung sudah menerapkan konsep STD dan memiliki dimensi STD yang diaplikasikan dalam konteks pariwisata. Meskipun demikan, belum seluruh dimensi dapat diterapkan pada studi ini, seperti $21^{\text {th }}$ century tourist information, Augmented Reality (AR), dan Virtual Reality (VR), karena belum tersedia di destinasi Kota Bandung. Menurut Zygiaris (2013), agar mencapai akses luas untuk informasi, destinasi perlu untuk menyediakan akses yang tidak terbatas terhadap data untuk semua masyarakat melalui sebuah platform publik yang terawasi. Hal ini juga dibutuhkan untuk mengakui bahwa ada masyarakat yang tinggal dalam suatu destinasi wisata yang masih awam terhadap teknologi (Komninos, et.al, 2013). Dengan demikian, destinasi-destinasi harus fokus untuk mengedukasi masyarakat dan wisatawan, sehubungan dengan pemakaian teknologi baru secara efisien. Oleh karena itu, jelas bahwa STD diperlukan untuk membangun kecerdasan dengan menerapkan aplikasi pariwisata yang sesuai dalam komponen smart city (Cohen, 2012).

\section{Tourist Experience}

Tourist experience diartikan sebagai perjalanan wisata yang pernah dilakukan di masa lalu (Larsen,2007). Tourist experience merupakan alur berkelanjutan yang terintegerasi antara perjalanan dan layanan dalam satu waktu yang terbatas dan biasanya dalam area geografis yang berbeda (Mendes et Al., 2010). Rivera (2013) mendefinisikan tourist experience sebagai pengalaman personal, menggambarkan aspek yang dapat dinyatakan, baik secara jelas ataupun tidak, memberikan dampak dari keunikan dan pengalaman yang mengesankan. Merujuk pada Rivera (2013), tourist experience mencakup physical, emotional, sensory, spiritual, dan pengalaman intelektual yang dapat dirasakan oleh wisatawan secara subjektif, mulai dari wisatawan merencanakan perjalanannya sampai ke tempat tujuan dan menikmati kegiatan wisatanya hingga kembali ke tempat mereka berasal, yang dilanjutkan dengan mengenang kembai perjalan wisatanya. Hal ini sejalan dengan definisi tourist experience yang diungkapkan oleh Ryan (2002), yang menemukan bahwa hasil dari pengalamanpengalaman tersebut berhubungan dengan keseluruhan perjalanan wisata yang mereka alami yang dapat menentukan kepuasan atau ketidakpuasan. Semua evaluasi ini dapat dipengaruhi oleh elemen-elemen personal, seperti knowledge, memory, perception, emotion dan self-identity. Melalui elemen tersebut dapat dilihat hasil yang dapat mengubah dan meningkatkan pengalaman melalui reflection dan recollection yang dapat mempengaruhi pengalaman itu sendiri (Ryan, 2002). Sementara Carballo, et.al (2015) menemukan proses kumulatif yang terdiri dar 3 fase: sebelum perjalanan, selama berlangsung kegiatan pada destinasi, dan setelah perjalanan; keseluruhan hal tersebut membutuhkan persiapan yang matang untuk dapat terjadi. Berdasarkan beberapa pengertian mengenai tourist experience, dapat ditegaskan bahwa pengalaman wisatawan di tempat tujuan wisata membentuk pikiran wisatawan melalui proses dari kedalaman perasaan dan nalar panca indera, kognitif, serta pengalaman secara emosional dalam suatu jangka waktu perjalanan, mulai dari rencana perjalanan wisata sampai kembali ke tempat asal.

Pengembangan STD dengan beragam unsur teknologi terkini dalam kegiatan wisata telah meningkatkan keingintahuan wisatawan terhadap satu destinasi secara digital. Ketersediaan beragam infrastruktur berbasis digital sebagai bagian dari fasilitas pariwisata meningkatkan kemudahan wisatawan dalam mencari informasi dan melakukan kontak dengan beragam penyedia layanan pariwisata. Tentunya, perkembangan digital dalam 
bidang pariwisata pada destinasi bertujuan untuk meningkatkan pengalaman berwisata.

Penelitian ini membahas mengenai Smart Tourism Destination (STD) untuk meningkatkan tourist experience di Kota Bandung. Kota Bandung telah menerapkan konsep smart city yang menjadi akar dari Smart Tourism Destination dan digital destination. Kota Bandung sudah menyediakan free wi-fi sebanyak 10.000 akses (Kamil, 2014), penggunaan teknologi lainnya yang sudah diterapkan di Kota Bandung adalah $Q R$-Codes. Dari beberapa teori yang sudah dipaparkan dalam penelitian ini, dengan fenomena yang terjadi, teori Smart Tourism Destination dari de Ávila, Lancis et.al (2015) cocok digunakan di Kota Bandung, di mana ada empat pondasi untuk dimensi STD, diantaranya adalah teknologi (21 $1^{\text {th }}$ century tourist information, free wi-fi, mobile apps, $Q R$ Codes, online maps), inovasi (promosi wisata online, komunikasi dengan aplikasi online, pengembangan produk wisata), aksesibilitas (kemudahan transportasi wisata, akses layanan informasi wisata) dan sustainability (peningkatan perdagangan/ perkebunan, kerajinan tangan, pemeliharaan warisan budaya).

\section{METODE PENELITIAN}

Metode dalam penelitian ini berisi mengenai langkah dan tata cara yang digunakan untuk mendapatkan serta mengolah data dari variabel smart tourism destination (X) dan tourist experience (Y). Penelitian ini membahas mengenai STD dalam meningkatkan tourist experience di Kota Bandung. Variabel bebas (independent variabel) yaitu STD (X) lalu variabel terikat (dependent variable) yaitu tourist experience (Y). Objek dalam penelitian ini adalah para wisatawan di Bandung yang menggunakan smartphone. Penelitian ini dilakukan menggunakan unit analisis yaitu STD dan tourist experience untuk wisatawan yang mengunjungi Bandung. Penelitian ini dilakukan kurang dari satu tahun, pada bulan Februari 2019 sampai Desember 2019. Oleh karena itu, penulis menggunakan metode cross-sectional, di mana informasi dikumpulkan dari setiap populasi sampel dan pada waktu tertentu hanya dilakukan sekali (Sumarwan, 2011). Penelitian ini menggunakan metode analisis deskriptif dan verifikatif. Agar nilai variabel bebas diketahui, dilakukan metode analisis deskriptif. Penulis menggunakan metode penelitian ini karena ingin mengetahui nilai variabel bebas, baik satu variabel atau lebih tanpa membuat bandingan atau menghubungkan antara variabel satu dengan variabel yang lain (Sugiyono, 2013). Untuk menyelidiki fenomena dan kunci permasalahan dari penelitian, penulis menggunakan analisis deskriptif. Dengan penelitian deskriptif, penulis memperoleh gambaran mengenai: 1) STD di Bandung dan 2) tourist experience di Bandung. Untuk menguji hipotesis yang telah ditetapkan, metode analisis verifikatif dilakukan terhadap populasi atau sampel tertentu (Sugiyono, 2013), maka akan diperoleh penjelasan sebagai berikut:

H1: Terdapat pengaruh STD terhadap tourist experience di Kota Bandung.

Sumber data primer didapatkan melalui penyebaran kuesioner dengan responden wisatawan di Kota Bandung. Sementara data sekunder diperoleh melalui wawancara dengan Dinas Kebudayaan dan Pariwisata Kota Bandung juga dengan pengamatan langsung di Bandung. Objek yang akan diteliti terdapat dalam sebuah penelitian yang disebut dengan populasi. Populasi dalam penelitian tidak hanya berupa orang, tetapi dapat juga sebagai benda. Populasi dalam penelitian dilakukan untuk dapat mempelajari seluruh karakteristik yang dimiliki oleh setiap orang atau objek tertentu. Sampel akan dibutuhkan apabila jumlah populasi sangat banyak dan sulit dijangkau oleh peneliti. Dengan demikian, jumlah sampel dari suatu populasi harus ditentukan dan ditetapkan dengan teknik sampling yang akan digunakan oleh peneliti. Penulis menentukan wisatawan di Kota Bandung sebagai sebagai populasi dalam penelitian ini. Jumlah kunjungan wisatawan ke Bandung menurut data akhir 
pada tahun 2017 adalah sebesar 4.801 .108 orang.

Dikarenakan populasi penelitian ini berjumlah besar, maka penulis menggunakan teknik sampling slovin dalam menentukan jumlah sampel minimal. Jumlah sampel yang dibutuhkan untuk penelitian ini adalah 400 wisatawan, akan tetapi penulis menyebarkan 450 kuesioner untuk lebih menegaskan hasil penelitian. Kuesioner disebarkan kepada wisatawan yang menggunakan smartphone untuk berwisata di Bandung. Teknik pengumpulan data dilakukan oleh penulis untuk mengumpulkan data-data yang telah didapatkan dan pada akhirnya diolah dan didapatkan untuk menguji perumusan hipotesis juga menegaskan hasil dari penelitian tersebut. Teknik pengumpulan data untuk penelitian ini adalah wawancara kepada Dinas Kebudayaan dan Pariwisata Kota Bandung dengan Bapak Indra Andika Arifiana, S.Sos, M.AP sebagai kepala seksi promosi pariwisata.

Hal ini dilakukan untuk mengetahui dan melengkapi pendapat langsung serta saran terhadap STD dan Tourist Experience, lalu penyebaran kuesioner yang disebarkan kepada wisatawan yang menggunakan smartphone di Bandung. Hal ini bertujuan untuk mengetahui kumpulan jawaban dari wisatawan mengenai STD dan tourist experience di Bandung serta karakteristik wisatawan tersebut secara detail. Kuesioner dibagikan di tempat-tempat wisata di Bandung. Kuesioner ini berupa cetakan yang dapat diisi secara online menggunakan google form untuk mempermudah responden dalam pengisian kuesioner. Observasi juga dilakukan untuk meneliti lingkungan objek penelitian yang mendukung kegiatan penelitian di Bandung. Pengujian ini dilakukan dengan dua cara, yaitu validitas dan realibilitas. Dengan kedua hal tersebut, penulis akan mengetahui tepat dan andalnya suatu alat ukur dalam penelitian. Uji validitas dilakukan untuk ukuran tingkat ketepatan dan konsistennya setiap data dari instrumeninstrumen penelitian. Dalam penelitian ini, yang akan diuji adalah STD sebagai variabel
$\mathrm{X}$ dan tourist experience sebagai variabel Y. Pengujian ini dilakukan dengan penyebaran kuesioner kepada 30 responden. Uji realibitias merupakan uji keandalan suatu alat ukur dalam penelitian. Hal ini dilakukan untuk mengetahui sejauh mana ukuran hasil dengan menggunakan suatu objek yang sama (Sugiyono, 2013). Hasil penelitian berarti andal apabila adanya kesamaan data dalam waktu yang berbeda. Apabila pada waktu yang sama alat ukur dapat digunakan berulang-ulang untuk mengukur objek yang sama dalam waktu yang berbeda dan suatu hasil menunjukkan kesamaan, maka alat ukur tersebut reliabel. Dari hasil pengujian validitas dan realibilitas, seluruh komponen dalam STD dan tourist experience di penelitian ini dinyatakan positif dan dapat dipakai sebagai alat ukur. Analisis linear berganda digunakan dalam penelitian ini.

Peneliti bermaksud memperkirakan bagaimana keadaan (turun naiknya) variabel dependen (kriterium), apabila ada dua atau lebih variabel independen sebagai faktor perkiraan dimanipulasi (diturun naikan nilainya) Sugiyono (2017). Dampak dari penggunaan analisis regresi adalah untuk dapat memutuskan apakah pengaruh STD (X) terhadap tourist experience (Y) naik atau turun. Setelah menganalisis data menggunakan analisis linear berganda, peneliti melakukan pengujian hipotesis berkaitan dengan ada tidaknya pengaruh $S T D$ terhadap tourist experience.

\section{HASIL DAN PEMBAHASAN}

Bagian ini berisi paparan dan perhitungan hasil dari penelitian serta pembahasan mengenai variabel yang diteliti, yaitu smart tourism destination (X) dan tourist experience $(\mathrm{Y})$ yang dilakukan di Kota Bandung. Selain itu, penelitian ini juga berisi karakteristik responden dalam kuesioner yang telah disebarkan kepada 450 responden di Kota Bandung kepada wisatawan yang menggunakan smartphone.

Karakteristik responden pada penelitian ini dibagi berdasarkan jenis kelamin, usia, status, pendidikan tertinggi, pengguna internet 
aktif, dan biaya yang dikeluarkan untuk internet per bulan. Berdasarkan jenis kelamin, wisatawan yang datang ke Kota Bandung sebagian besar adalah perempuan sebanyak 239 orang $(53,2 \%)$, sedangkan wisatawan laki-laki sebanyak 211 orang $(46,8 \%)$. Aktivitas wisata yang dilaksanakan di Bandung banyak diminati oleh wisatawan perempuan, karena atraksi wisata yang paling banyak diminati di Kota Bandung adalah kuliner dan fashion. Berdasarkan usia, wisatawan yang datang ke Kota Bandung sebagian besar berusia 18-25 tahun sebanyak 120 orang $(26,6 \%)$ dan hasil terendah ada di rentang $>50$ tahun sebanyak 35 orang. Hal ini menggambarkan bahwa wisatawan pada rentang usia 18-30 tahun menggunakan smartphone untuk melakukan aktivitas wisata di Bandung, sedangkan pada usia di atas 50 tahun merupakan wisatawan yang biasanya ingin melakukan perjalanan wisata secara instan. Selanjutnya, klasifikasi responden berdasarkan status diketahui bahwa wisatawan yang datang ke Bandung sebagian besar sudah menikah sebanyak 287 orang $(63,8 \%)$. Berdasarkan pendidikan, diketahui bahwa wisatawan yang datang ke Bandung sebagian besar berpendidikan S1 sebanyak 165 orang $(36,6 \%)$. Diketahui juga bahwa wisatawan yang datang ke Kota Bandung sebagian besar merupakan pengguna internet aktif sebanyak 386 orang (88\%). Hal ini menggambarkan bahwa wisatawan di Kota Bandung mencari segala informasi berwisata melalui internet dalam melakukan aktivitas wisata. Berdasarkan pengeluaran internet per bulan, diketahui bahwa wisatawan yang datang ke Bandung sebagian besar mengeluarkan biaya $>200.000$ per bulan untuk internet sebanyak 159 orang $(35,3 \%)$. Hal ini menggambarkan bahwa para wisatawan sebagian besar pengguna internet aktif, sehingga biaya yang dikeluarkan pun cukup besar akibat selalu digunakan untuk mencari segala informasi wisata, seperti video wisata, browsing situs-situs wisata, dan membagikan aktivitas wisata mereka di media sosial. Hasil tanggapan responden terhadap STD dan tourist experience pada setiap dimensi dan indikatornya dianalisis pada tabel 2 dan 3 di bawah ini:

Tabel 2. Hasil Tanggapan Responden terhadap $S T D$

\begin{tabular}{|c|c|c|c|}
\hline Sub Variabel & No & Indikator & $\begin{array}{l}\text { Total } \\
\%\end{array}$ \\
\hline \multirow[t]{6}{*}{ Technology } & $\begin{array}{rr}1 & \mathrm{~J} \\
& \mathrm{c} \\
\mathrm{t} & \\
\mathrm{t} & \end{array}$ & $\begin{array}{l}\text { Jaringan free } w i \text {-fi di } \\
\text { destinasi wisata } \\
\text { tersedia dengan baik }\end{array}$ & 68.36 \\
\hline & $\begin{array}{cc}2 & 1 \\
& 1 \\
& 1 \\
1 & 1\end{array}$ & $\begin{array}{l}\text { Mengakses peta } \\
\text { melalui smartphone di } \\
\text { destinasi wisata } \\
\text { mudah }\end{array}$ & 66.13 \\
\hline & $\begin{array}{rr}3 \\
1 \\
1 \\
\\
2\end{array}$ & $\begin{array}{l}\text { QR Codes dapat } \\
\text { mempermudah } \\
\text { aktivitas wisata }\end{array}$ & 65.96 \\
\hline & $\begin{array}{rr} \\
1 \\
\\
c \\
1 \\
1\end{array}$ & $\begin{array}{l}\text { Mendapatkan video } \\
\text { atau tayangan tentang } \\
\text { destinasi wisata } \\
\text { mudah }\end{array}$ & 66.31 \\
\hline & & Persentase & 66.69 \\
\hline & & Kriteria & Cukup \\
\hline \multirow[t]{6}{*}{ Innovation } & 5 & $\begin{array}{l}\text { Promosi destinasi } \\
\text { wisata pada media } \\
\text { sosial sudah berjalan } \\
\text { dengan baik }\end{array}$ & 65.96 \\
\hline & $\begin{array}{ll}6 & 1 \\
& 1 \\
& 1\end{array}$ & $\begin{array}{l}\text { Mudah berkomunikasi } \\
\text { melalui media sosial }\end{array}$ & 65.73 \\
\hline & 7 & $\begin{array}{l}\text { Komunikasi melalui } \\
\text { aplikasi online } \\
\text { dengan destinasi } \\
\text { wisata dapat diakses } \\
\text { dengan mudah }\end{array}$ & 67.78 \\
\hline & 8 & $\begin{array}{l}\text { Inovasi produk di } \\
\text { destinasi wisata sudah } \\
\text { baik }\end{array}$ & 66.71 \\
\hline & & Persentase & 66.54 \\
\hline & & Kriteria & Cukup \\
\hline \multirow[t]{4}{*}{ Accesibility } & 9 & $\begin{array}{l}\text { Pelayanan informasi } \\
\text { di destinasi wisata } \\
\text { mudah }\end{array}$ & 66.27 \\
\hline & 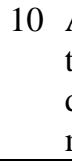 & $\begin{array}{l}\text { Akses penggunaan } \\
\text { transportasi ke } \\
\text { destinasi wisata } \\
\text { mudah }\end{array}$ & 66.40 \\
\hline & & Persentase & 66.33 \\
\hline & & Kriteria & $\overline{\text { Cukup }}$ \\
\hline \multirow[t]{3}{*}{ Sustainability } & $11 \mathrm{I}$ & $\begin{array}{l}\text { Peningkatan } \\
\text { perdagangan } \\
\text { (kerajinan, } \\
\text { perkebunan, dll.) di } \\
\text { destinasi wisata }\end{array}$ & 65.96 \\
\hline & & $\begin{array}{l}\text { Pemeliharaan warisan } \\
\text { budaya di Kota } \\
\text { Bandung baik }\end{array}$ & 68.44 \\
\hline & & Persentase & 67.20 \\
\hline
\end{tabular}


Sumber: Olahan peneliti, 2019

Kriteria Cukup

Tabel 3. Hasil Tanggapan Responden terhadap Tourist Experience

\begin{tabular}{|c|c|c|c|}
\hline $\begin{array}{c}\text { Sub } \\
\text { Variabel } \\
\end{array}$ & No & Indikator & $\%$ \\
\hline \multirow[t]{4}{*}{ Knowledge } & 1 & $\begin{array}{l}\text { Mudah memperoleh } \\
\text { pengetahuan di destinasi } \\
\text { wisata yang Anda } \\
\text { kunjungi }\end{array}$ & 71.78 \\
\hline & 2 & $\begin{array}{l}\text { Apakah mudah } \\
\text { memperoleh informasi di } \\
\text { destinasi wisata yang } \\
\text { Anda kunjungi? }\end{array}$ & 64.89 \\
\hline & & Persentase & 68.33 \\
\hline & & Kriteria & Baik \\
\hline \multirow[t]{4}{*}{ Memory } & 3 & $\begin{array}{l}\text { Destinasi wisata di Kota } \\
\text { Bandung berkesan }\end{array}$ & 66.80 \\
\hline & 4 & $\begin{array}{l}\text { Anda menginginkan } \\
\text { update pada media soaial } \\
\text { saat berwisata di Kota } \\
\text { Bandung }\end{array}$ & 64.58 \\
\hline & & Persentase & 65.69 \\
\hline & & Kriteria & Cukup \\
\hline \multirow[t]{6}{*}{ Perception } & 1 & $\begin{array}{l}\text { Destinasi wisata di Kota } \\
\text { Bandung menarik }\end{array}$ & 65.69 \\
\hline & 2 & $\begin{array}{l}\text { Teknologi penunjang } \\
\text { wisata di Kota Bandung } \\
\text { canggih }\end{array}$ & 66.89 \\
\hline & 3 & $\begin{array}{l}\text { Akses ke destinasi di } \\
\text { kota Bandung mudah }\end{array}$ & 64.49 \\
\hline & 4 & $\begin{array}{l}\text { Masyarakat lokal Kota } \\
\text { Bandung sudah mengenal } \\
\text { dengan baik teknologi }\end{array}$ & 63.24 \\
\hline & & Persentase & 65.08 \\
\hline & & Kriteria & Cukup \\
\hline \multirow[t]{4}{*}{ Emotion } & 1 & $\begin{array}{l}\text { Anda merasa senang } \\
\text { berkunjung ke Kota } \\
\text { Bandung } \\
\end{array}$ & 63.33 \\
\hline & 2 & $\begin{array}{l}\text { Anda merasa ingin lagi } \\
\text { berkunjung ke Kota } \\
\text { Bandung }\end{array}$ & 63.24 \\
\hline & & Persentase & 66.76 \\
\hline & & Kriteria & Cukup \\
\hline \multirow[t]{3}{*}{$\begin{array}{c}\text { Self } \\
\text { Identity }\end{array}$} & 1 & $\begin{array}{l}\text { Wisatawan merasa } \\
\text { bangga berkunjung ke } \\
\text { Kota Bandung }\end{array}$ & 66.76 \\
\hline & 2 & $\begin{array}{l}\text { Anda merasa senang } \\
\text { berbagi pengalaman } \\
\text { Anda di Kota Bandung } \\
\text { kepada orang lain } \\
\text { melalui media sosial }\end{array}$ & 66.76 \\
\hline & & $\begin{array}{c}\text { Persentase } \\
\text { Kriteria }\end{array}$ & $\begin{array}{c}66.76 \\
\text { Cukup }\end{array}$ \\
\hline
\end{tabular}

Sumber: Olahan peneliti, 2019

Berdasarkan pada penilaian keseluruhan variabel dan dimensi STD, maka hasil rekapitulasi seluruh tanggapan responden disajikan dalam Tabel 4:

Tabel 4. Rekapitulasi Hasil Tanggapan Responden terhadap STD

\begin{tabular}{llll}
\hline No & Dimensi & \% & Kriteria \\
\hline 1 & Technology & 66.69 & Cukup \\
\hline 2 & Innovation & 66.54 & Cukup \\
\hline 3 & Accesibility & 66.33 & Cukup \\
\hline 4 & Sustainability & 67.20 & Cukup \\
\hline Total & & $\mathbf{6 6 , 6 9}$ & Cukup \\
\hline
\end{tabular}

Sumber: Olahan peneliti, 2019

Berdasarkan data pada Tabel 4, dapat disimpulkan bahwa variabel Smart Tourism Destination dengan persentase sebesar $66.69 \%$, dengan dimensi sustainability yang mendapatkan penilaian paling tinggi sebesar $67.20 \%$ dan dimensi accesibility yang mendapatkan penilaian paling rendah sebesar $66.33 \%$. Berdasarkan wawancara dengan Bapak Indra dari Disbudpar Kota Bandung, Kota Bandung masih memiliki tempat wisata yang masih terus menyalurkan kebudayaan dan kesenian Kota Bandung, seperti Dago Tea House, Baranang Siang, dan juga Saung Angklung Udjo yang masih terus bisa berkomunikasi serta mengajak langsung wisatawan untuk berbagi pengalaman kebudayaan dan kesenian khas Kota Bandung, baik secara langsung ataupun melalui media sosial.

Secara teknologi, Kota Bandung telah memiliki free wifi di tempat-tempat wisata dan juga di tempat umum. Untuk mendapatkan video di Kota Bandung sudah mudah. Selain dapat diakses melalui web atau situs resmi Kota Bandung, video tersebut juga biasanya diputar pada videotron di depan Gasibu, Jl. Riau, dan Jl. Gatot Subroto yang biasanya menayangkan video promosi wisata Kota Bandung.

Salah satu $Q R$ Codes yang dapat digunakan di Kota Bandung adalah BOSEH (Bikes on the Street Everybody Happy), akan tetapi masih harus lebih disosialisasikan kepada wisatawan agar mereka tahu di mana letak-letak $Q R$ Codes yang dapat digunakan untuk aktivitas beriwsata. Aksesibilitas di 
Bandung juga sudah cukup baik dengan adanya dukungan Dinas Budaya dan Pariwisata (Disbudpar) Kota Bandung. Salah satu perjanjian kerja sama Disbudpar Kota Bandung dengan Grab adalah sebagai penghubung untuk memajukan sektor pariwisata di Kota Bandung (wisatabdg.com, 2018), tetapi pemilihan-pemilihan jalan ke destinasi melalui maps online harus tetap ditingkatkan agar dapat menghindari kemacetan. Inovasi dilakukan dengan Grab Wisata yang di dalamnya terdapat video "selamat datang di Kota Bandung" dengan musik khas Sunda. Berdasarkan pada penilaian keseluruhan variabel dan dimensi tourist experience, hasil rekapitulasi tanggapan responden disajikan dalam Tabel 5 berikut ini:

Tabel 5. Rekapitulasi Hasil Tanggapan Responden terhadap Tourist Experience

\begin{tabular}{clcc}
\hline No & Dimensi & Persentase & Kriteria \\
\hline $\mathbf{1}$ & Knowledge & 68.33 & Baik \\
\hline $\mathbf{2}$ & Memory & 65.69 & Cukup \\
\hline $\mathbf{3}$ & Perception & 65.08 & Cukup \\
\hline $\mathbf{4}$ & Emotion & 63.29 & Cukup \\
\hline $\mathbf{5}$ & Self Identity & 66.76 & Cukup \\
\hline & Total & $\mathbf{6 5 . 8 3}$ & Cukup
\end{tabular}

Sumber: Olahan peneliti, 2019

Berdasarkan pada Tabel 5 dapat disimpulkan bahwa variabel tourist experience dengan persentase sebesar $65.83 \%$ dengan dimensi knowledge yang mendapatkan penilaian paling tinggi sebesar $68.33 \%$ dan dimensi emotion yang mendapatkan penilaian paling rendah sebesar 63.29\%.

Pengalaman berwisata yang didapatkan paling banyak oleh wisatawan adalah mudahnya mendapatkan pengetahuan. Dengan adanya STD di Bandung, dapat menambah pengetahuan mereka lebih cepat dan mudah, yang diharapkan pengetahuan dan pengalaman baik yang mereka alami di Bandung dapat disebarkan melalui media sosial, sehingga dapat menarik wisatawan lain untuk datang ke Bandung.

Analisis regresi linear berganda digunakan dalam penelitian ini untuk mencari tahu seberapa besar pengaruh STD terhadap tourist experience di Bandung. Berikut merupakan hasil perhitungan persamaan analisis regresi linear berganda pada Tabel 6:

Tabel 6. Analisis Linear Berganda

\begin{tabular}{|c|c|c|c|c|c|c|}
\hline \multicolumn{7}{|c|}{ Coefficients $^{\mathrm{a}}$} \\
\hline $\begin{array}{r}\text { Mo } \\
\text { del }\end{array}$ & & $\begin{array}{c}\text { Unstandard } \\
\text { ized } \\
\text { Coefficient }\end{array}$ & & $\begin{array}{c}\text { Standardi } \\
\text { zed } \\
\text { Coefficien } \\
\text { ts }\end{array}$ & $\mathbf{t}$ & $\begin{array}{c}\mathrm{Si} \\
\mathrm{g}\end{array}$ \\
\hline & & B & $\begin{array}{r}\text { Std. } \\
\text { Erro }\end{array}$ & Beta & & \\
\hline 1 & $\begin{array}{c}\text { (Consta } \\
\text { nt) }\end{array}$ & 25.291 & .564 & & $\begin{array}{c}44.87 \\
2 \\
\end{array}$ & .000 \\
\hline & $\mathrm{X} 1$ & .200 & .020 & .464 & 9.829 & .000 \\
\hline
\end{tabular}

a. Dependent Variable: $\mathrm{Y}$

Sumber: Olahan peneliti, 2019

Berdasarkan penilaian di atas, dapat disimpulkan bahwa apabila variabel STD sama dengan nol atau konstan, maka tourist experience memiliki nilai sebesar 25.291 satuan, sedangkan koefisien regresi STD terhadap tourist experience sebesar 0.200 yang berarti bahwa setiap penambahan variabel STD di Kota Bandung akan menaikkan tourist experience sebesar 0.200.

\begin{tabular}{cc}
\multicolumn{2}{c}{ Tabel 7. Interpretasi Koefisien Korelasi } \\
\hline Interval Koefisien & Tingkat Hubungan \\
\hline $0.000-0.199$ & Sangat Rendah \\
\hline $0.200-0.399$ & Rendah \\
\hline $0.400-0.599$ & Sedang \\
\hline $0.600-0.799$ & Kuat \\
\hline $0.800-1.000$ & Sangat Kuat \\
\hline
\end{tabular}

Sumber: Sugiyono, 2017

Tabel 8. Matriks Korelasi Variabel $S T D$ terhadap Tourist Experience

\begin{tabular}{lrrr}
\hline \multicolumn{4}{c}{ Correlations } \\
\hline & & \multicolumn{1}{c}{ Y } & \multicolumn{1}{c}{ X1 } \\
\hline Pearson Correlation & $\mathrm{Y}$ & 1.000 & .741 \\
\cline { 2 - 4 } & $\mathrm{X}$ & .741 & 1.000 \\
\hline \multirow{2}{*}{ Sig. (1-tailed) } & $\mathrm{Y}$ &. & .000 \\
\cline { 2 - 4 } & $\mathrm{X}$ & .000 &. \\
\hline $\mathrm{N}$ & $\mathrm{Y}$ & 450 & 450 \\
\cline { 2 - 4 } & $\mathrm{X}$ & 450 & 450 \\
\hline
\end{tabular}

Sumber: Olahan peneliti, 2019

Berdasarkan hasil pengolahan data pada Tabel 8 dengan SPSS v25, didapatkan hasil korelasi antara STD (X) dengan tourist experience $(\mathrm{Y})=0.741$. Hal ini berarti 
terdapat hubungan yang kuat, karena berkisar antara 0.600-0.799 (Sugiyono, 2017).

Hipotesis dalam penelitian ini adalah STD (X) berpengaruh terhadap tourist experience (Y). Uji hipotesis ini menggunakan uji $\mathrm{F}$ sebagai alat statistik ujinya dengan membandingkan antara $\mathrm{F}$ hitung dengan $\mathrm{F}$ tabel, yaitu apabila $\mathrm{F}$ hitung lebih besar dari $\mathrm{F}$ tabel, maka dapat diartikan bahwa terdapat pengaruh yang signifikan antara variabel STD terhadap tourist experience. Sementara apabila F hitung lebih kecil dari F tabel, dapat diartikan bahwa tidak terdapat pengaruh signifikan antara STD terhadap tourist experience.

Tabel 9. Uji Secara Simultan STD terhadap Tourist Experience

\begin{tabular}{lccccc}
\hline \multicolumn{5}{c}{ ANOVA $^{\mathbf{a}}$} \\
\hline Model & $\begin{array}{c}\text { Sum of } \\
\text { Squares }\end{array}$ & df & $\begin{array}{c}\text { Mean } \\
\text { Square }\end{array}$ & F & Sig. \\
Regression & 6156.893 & 2 & 3078.447 & 336.374 & $.000^{\mathrm{b}}$ \\
\hline Residual & 4090.885 & 447 & 9.152 & \\
\hline Total & 10247.778 & 449 & & \\
\hline a. Dependent Variable: Y \\
\hline b. Predictors: (Constant), X \\
\hline Sumber: Olahan peneliti, 2019
\end{tabular}

Berdasarkan Tabel 9 di atas, hasil menunjukkan F hitung bernilai 336.374, dan F tabel bernilai 3.02. Hal ini berarti bahwa STD secara simultan berpengaruh terhadap tourist experience. Sementara secara parsial, hipotesisnya dapat dijelaskan ke dalam bentuk statistik dibawah ini:

Ho: $\beta_{1}=0$ : Tidak terdapat pengaruh antara STD terhadap tourist experience.

Ha: $\beta_{1} \neq 0$ : Terdapat pengaruh antara $S T D$ terhadap tourist experience.

Setelah pengujian secara parsial dilakukan, $\mathrm{t}$ hitung dan $\mathrm{t}$ tabel akan dibandingkan dengan menggunakan uji two tailed dengan taraf kesalahan 5\% (Sugiyono, 2013). Ketentuannya apabila t hitung lebih besar daripada $t$ tabel, berarti ada pengaruh antar variabel, sedangkan apabila $t$ hitung lebih kecil daripada $t$ tabel, maka tidak ada pengaruh antar variabel.

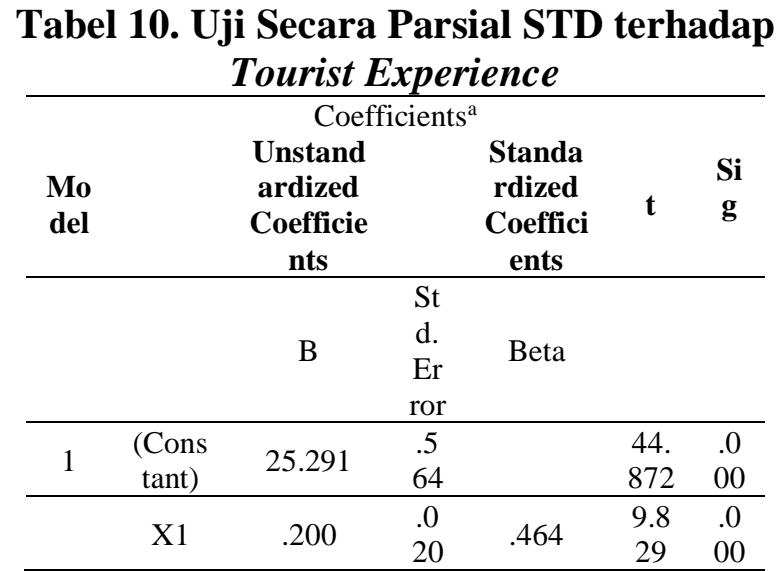

Sumber: Olahan peneliti, 2019

Pada Tabel 10 dapat dilihat nilai t hitung pada variabel $S T D$ terhadap tourist experience adalah $9.829 \quad(8,98)$. Jika dibandingkan dengan $t$ tabel secara umum yang bernilai 1,96, maka t hitung lebih besar dari t tabel. Dari hasil tersebut, variabel STD terhadap tourist experience mempunyai pengaruh yang signifikan secara parsial. Secara teknologi, Bandung telah memiliki free wifi di tempattempat wisata dan juga di tempat umum. Untuk mendapatkan video di Bandung sudah mudah, selain dapat diakses melalui web atau situs resmi Kota Bandung, video tersebut juga biasanya diputar pada videotron di depan Gasibu, Jl. Riau, dan Jl. Gatot Subroto yang biasanya menayangkan video promosi wisata Bandung. Salah satu $Q R$ Codes yang dapat digunakan di Kota Bandung adalah BOSEH (Bikes on the Street Everybody Happy), akan tetapi masih harus lebih disosialisasikan kepada wisatawan agar mereka tahu di mana letak-letak $Q R$ Codes yang dapat digunakan untuk aktivitas beriwsata.

Aksesibilitas di Bandung juga sudah cukup baik dengan gencarnya reservasi secara online untuk memudahkan wisatawan dalam pemesanan akomodasi juga transportasi dengan adanya dukungan Dinas Budaya dan Pariwisata (Disbudpar) Kota Bandung. Salah satu perjanjian kerja sama Disbudpar Kota Bandung dengan Grab adalah sebagai penghubung untuk memajukan sektor pariwisata di Bandung, tetapi pemilihanpemilihan jalan ke destinasi melalui maps online harus tetap ditingkatkan, sehingga dapat menghindari kemacetan. Inovasi 
dilakukan dengan Grab Wisata, yang didalamnya terdapat video "selamat datang di Kota Bandung" dengan musik khas Sunda. Pengalaman berwisata yang didapatkan paling banyak oleh wisatawan adalah mudahnya mendapatkan pengetahuan. Adanya STD di Bandung dapat menambah pengetahuan mereka lebih cepat dan mudah, yang diharapkan pengetahuan serta pengalaman baik yang mereka alami di Bandung dapat disebarkan melalui media sosial, sehingga dapat menarik wisatawan lain untuk datang ke Bandung. Secara signifikan, STD dapat mempengaruhi tourist experience di Bandung.

\section{KESIMPULAN}

Penelitian ini hanya membahas mengenai pengaruh dari STD terhadap tourist experience. Hasil penelitian ini dapat dijadikan acuan untuk penerapan pengembangan konsep STD di Bandung di masa yang akan datang, seperti penyediaan tourist information di pusat kota yang produktif, yang dapat berfungsi tidak hanya untuk menyediakan informasi di Bandung dan promosi suatu destinasi, tapi juga membantu pemasaran dan segmentasi produk di setiap wilayah berdasarkan preferensi pengunjung. Ini merupakan ruang inovasi yang akan dibangun sebagai referensi titik pertemuan antara wilayah dan pengunjung yang akan sering menggunakan teknologi dan aplikasi yang memperbolehkan pengunjung untuk tertarik terhadap sebuah destinasi. Sementara itu, di saat bersamaan, membuat suatu destinasi dapat mengumpulkan dan menganalisis banyak informasi yang dapat membawa pengunjung untuk datang. Kemudian, mengaplikasikan $Q R$ Codes lebih banyak untuk mempermudah wisatawan dalam melakukan pembayaran secara langsung pada atraksi wisata, rumah makan, akomodasi, dan lain-lain. Menerapkan konsep Green Hotel untuk mengurangi limbah dan polusi juga merencanakan konsep transportasi terpadu khusus untuk wisata di Bandung dengan menggunakan Bandung Tourism Pass untuk menambah pengalaman berwisata.
Penelitian selanjutnya dapat dilakukan secara kualitaitif untuk pengembangan konsep STD di Bandung.

\section{DAFTAR PUSTAKA}

Badan Pusat Statistik. (2018). Jumlah Kunjungan Wisman ke Indonesia Agustus 2018. Di Akses dari: https://www.bps.go.id/pressrelease/201 8/10/01/1476/jumlah-kunjunganwisman-ke-indonesia-agustus-2018mencapai-1-51-juta-kunjungan-.html

Buhalis, D., Amaranggana, A. (2014). Smart Tourism Destinations. Z. Xiang and I. Tussyadiah (eds.), Information and Communication Technologies in Tourism 2014, DOI: 10.1007/978-3319-03973-2_40, Springer International Publishing Switzerland

Carballo, F., Moreno, S., León, C., \& Ritchie, J. (2015). La creación y promoción de experiencias en un destino turístico: un análisis de la investigación y necesidades de actuación.Cuadernos de Turismo, (35), 71-94.

Cohen, B. (2012). "What exactly is a smart city."

De Ávila, Lancis \& Antonio López. (2015). "Smart Destination Report : building the future". SEGITTUR. Madrid

Del Chiappa, G. and Baggio, R. (2015), "Knowledge transfer in smart tourism destinations: analyzing the effects of a network structure", Journal of Destination Marketing \& Management, Vol. 30 No. 10, pp. 1757-1771, available at: http://doi.org/10.1016/j.jdmm.2015.02. 001

Gretzel, U., Werthner, H., Koo, C., \& Lamsfus, C. (2015). Conceptual foundations for understanding smart tourism ecosystems. Computers in Human Behavior, 50, 558-563. http://doi.org/10.1016/j.chb.2015.03.043

Jovicic, D. Z. (2017). From the traditional understanding of tourism destination to the smart tourism destination. Current Issues in Tourism, (In press), 
http://doi.org/10.1080/13683500.2017.131 3203

Kamil, Ridwan. (2014). Smart City Bandung. Komninos, N., Pallot, M., \& Schaffers, H. (2013). Special Issue on smart cities and the future Internet in Europe. Journal of the Knowledge Economy, 4(2), 119-134.

Koo, C., Yoo, K.-H., Lee, J.-N., \& Zanker, M. (2016). Special section on generative smart tourism systems and management: Man-machine interaction. International Journal of Information Management, 36(6), 1301-1305. http://doi.org/10.1016/j.ijinfomgt.2016.05. 015

Larsen, S. (2007). Aspects of a Psychology of the Tourist Experience, Scandinavian Journal of Hospitality and Tourism.

Lea, Rodger. (2017). Smart Cities: An Overview of the Technology Trends Driving Smart Cities. IEEE Advancing Technology for Humanity. United States License.

Mauludy, M. F. (2017). Begini Cara Menggunakan Sepeda Keliling Bandung melalui Obike. Di Akses dari: https://www.pikiran-rakyat.com/bandungraya/2017/12/20/begini-caramenggunakan-sepeda-keliling-bandungmelalui-obike-416303

Mendes, J., Valle, P., Guerreiro, M., \& Silva, J. (2010). The tourist experience: Exploring the relationship between tourist satisfaction and destination loyalty. Tourism, 58(2), 111-126.

Noor, A., Suryana, M., Amalia, S. (2019). Social Media-Based Behavior To Promote Tourist Destination. Vol. 35, No.21. Opcion, Scopus Index Q3. Http://produccioncientificaluz.org/inde x.php/opcion/article/view/29562

Pearce, D. G. (2014). Toward an Integrative Conceptual Framework of Destinations. Journal of Travel Research, 53(2), 141153. http://doi.org/10.1177/0047287513491334

Rivera, M. (2013). El turismo experiencial como forma de turismo responsable e intercultural. Universidad de Córdova,
Cátedra Intercultural (Eds). Jornadas sobre Investigación e Innova-ción para la Interculturalidad. (pp. 199-217) Córdoba, España

Ryan, C. (2002). From motivation to assessment. In C. Ryan (Ed.), The Tourist Experience (2nd Edition). London: Continuum.

Sugiyono. (2010). Metode Penelitian Pendidikan Pendekatan Kuantitatif, kualitatif, dan R\&D. Bandung: Alfabeta

Sugiyono. (2013). Metode Penelitian Kuantitatif, Kualitatif dan R\&D. Bandung: Alfabeta.CV

Sugiyono. (2017). Metode Penelitian Kuantitatif, Kualitatif, dan R\&D. Bandung : Alfabeta, CV.

Sumarwan. (2011). Riset Pemasaran dan Konsumen : Panduan Riset dan Kajian: Kepuasan, Perilaku Pembelian, Gaya Hidup, Loyalitas dan Persepsi Risiko,PT Penerbit IPB Press, Bogor.

Wisatabdg.com. (2018). Jelajah Wisata di Bandung Lebih Nyaman. Di Akses dari: https://www.wisatabdg.com/2018/11/jelaja h-wisata-di-bandung-lebih-nyaman.html

Zygiaris, S. (2013). Smart city reference model: Assisting planners to conceptualize the building of smart city innovation ecosystems. Journal of the Knowledge Economy, 4(2), 217-231. 